\title{
Designing a coaching intervention to support leaders promoted into senior positions
}

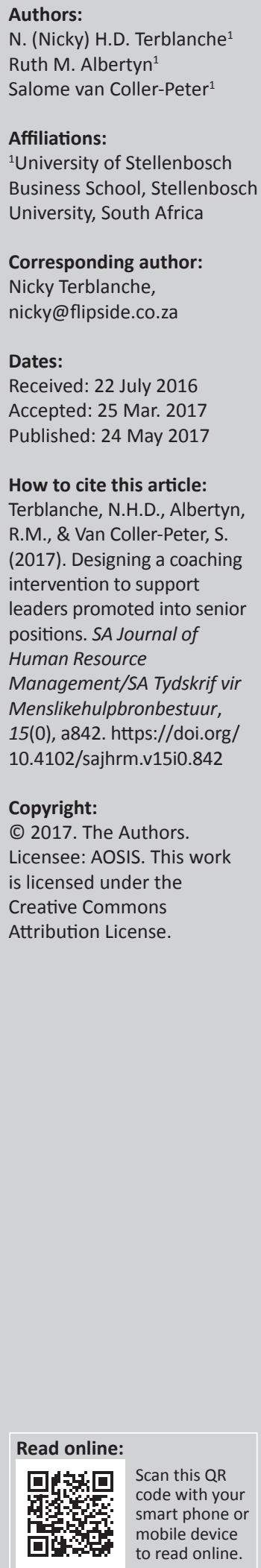

Orientation: Coaching is sometimes used in organisations to assist and support people when they are promoted into senior leadership positions. These coaching interventions are not optimally designed.

Research purpose: The objective of this research was to investigate how a transition coaching intervention should be designed to cater specifically for people promoted into senior leadership positions.

Motivation for the study: Leaders face daunting challenges when promoted into a senior position. Coaching could offer powerful support, but very little research exists on how to design a transition coaching intervention specifically aimed at supporting recently promoted senior leaders.

Research design, approach and method: A constructivist, grounded theory approach using purposeful, theoretical sampling was used to identify 16 participants (recently promoted senior leaders, coaches, Human Resource [HR] partners and a line manager) from various organisations with whom open-ended interviews were conducted on their experiences of coaching during a transition.

Main findings: Transition coaching is used reactively, started too late and was not continued for long enough. Transition coaching design should take cognisance of coach-coachee matching; goal setting that includes the organisation's goals; location of coaching session (away from the office); should include reflection and active experimentation; and use assessments and involving the line manager, mentors and the new leader's team in the process.

Practical and managerial implications: The findings of this research provide practical recommendations for applying coaching during transitions into senior leadership positions and may be useful to human resource practitioners when designing leadership support and succession planning interventions.

Contribution and value added: To address the serious and real possibility of failure once leaders are promoted, and to optimise the time and money spent on coaching during career transitions, this research provides insight into the design and execution of tailor-made transition coaching interventions to help recently promoted senior leaders succeed in their new role.

\section{Introduction}

\section{Problem statement}

\section{Key focus}

When leaders are promoted into senior positions ${ }^{1}$ they face serious challenges. Many fail to meet their objectives (Martin, 2015) or underperform (Sutton, 2008). Coaching is a strategy that is sometimes used to support recently promoted leaders, but there is a lack of empirical research around how a coaching intervention should be designed specifically to support career transitions. This research presents findings relating to when and how coaching should be used during senior career transitions and makes recommendations regarding tailoring a transition coaching intervention for senior career transitions.

\section{Background}

Building sustainable businesses is a challenge faced by many organisations today. A key element of organisational sustainability is effective leadership on all levels in the organisation and 1.The term 'senior leaders" in the context of this research refers to $C$-level executives and heads of business units up to two levels below the Clevel. 
especially at senior levels (Charan, Drotter \& Noel, 2011), and yet there is a serious shortage of effective organisational leaders in the world (Freedman, 2011; Oliver \& Page, 2017). The fast pace of corporate expansion requires leaders in organisations to move to new leadership levels at increasing speeds (Charan et al., 2011) and while many attempt the transition, fewer than a third fulfil their objectives (Martin, 2015) and up to $46 \%$ underperform (Sutton, 2008). A study conducted by Watkins (2009) showed that $87 \%$ of Human Resource (HR) professionals consider career transitions to be the most challenging event in a manager's career.

A career transition occurs when a leader is promoted to a more senior level in the organisation with more and different responsibilities. This occurs as a result of personal growth and ambition or structural changes in the workplace (Chinyamurindi, 2012). A senior career transition poses numerous challenges to the individual and the organisation. The incumbent is expected to 'hit the ground running' and complete the transition quickly (Sutton, 2008; Watkins, 2003); deal with higher levels of complexity and uncertainty (Dotlich, Noel \& Walker, 2004); work with longer time horizons (Jaques, 1996); and step out of the comfort zone of a specialist to take on strategic challenges (Peltier, 2010). There is also pressure on organisations to develop attractive employee value propositions to retain talented leaders, especially in the South African context (Nzukuma \& Bussin, 2011).

In order to support recently promoted senior leaders, organisations employ a number of support strategies including leadership development programmes, mentoring and coaching (Kombarakaran, Yang, Baker \& Fernandes, 2008). Coaching has been shown to be an effective leadership development tool (Peltier, 2010; Theeboom, Beersma \& Van Vianen, 2013), but the explicit use of transition coaching during promotion to a senior position has received little attention with only one empirical study found (Reynolds, 2011).

\section{Research objectives}

The question this study asks is: 'How should a coaching intervention be designed to explicitly support leaders who are promoted into senior positions?' To answer this question, there were two research objectives: firstly, to understand how and when coaching should be initiated during a career transition and secondly, to understand what aspects must be present during the coaching processes to optimally support recently promoted senior leaders.

\section{Contribution to field}

South Africa faces a shortage of skilled senior leaders in the corporate world (Nzukuma \& Bussin, 2011). The emerging field of coaching potentially offers a way to support recently promoted leaders, but very little empirical research has been conducted to understand how transition coaching can be employed during senior career transitions. This study may benefit designers of leadership development and support programmes, recently promoted senior leaders and coaches and coach trainers by providing specific guidelines for designing and conducting transition coaching for senior leaders.

\section{Literature review}

Leadership development theory with a focus on career transitions and coaching theory with a focus on transition coaching form the theoretical underpinnings of this research. This section reviews recent relevant publications in these fields and shows the significance of the challenges faced by recently promoted leaders, as well as the lack of empirical research on transition coaching.

\section{Leadership development and transitions}

Several theories of leadership career transitions, leadership levels and leadership developmental stages exist. The wellknown 'Leadership Pipeline' model brought attention to the fact that there are different levels of leadership within an organisation with each level requiring different skills. Leaders transition through six levels: managing self, managing other, managing managers, functional managers, business managers, group manager and enterprise manager (Charan et al., 2011). Each stage requires leaders to let go of certain thinking and behavioural patterns and learn new ones. The focus of this research is career transitions at the higher end of this pipeline, including business, group and enterprise managers. At these levels, leaders have to learn to deal with higher levels of complexity and take a more strategic organisational view. The chances of failure at these senior levels are high and the impact of failure is significantly damaging to both the individual and the organisation (Manderscheid \& Ardichvili, 2008; Martin \& Gentry, 2011). Ensuring a successful transition therefore becomes an imperative and further highlights the need for support in the form of interventions such as transition coaching.

A different perspective on leadership levels is Jaques' Stratified Systems Theory that defines work in organisations in seven strata on a basis of decision-making complexity where each level of work is related to the time span required by the executor of the task to complete the task (Jaques, 1996). This theory supports the view of Charan et al. that different skills and abilities are required by leaders operating at different levels and reinforces the view that change and transformation are required to successfully execute at a new level. By implication then, if a leader is promoted to the next level, the leader needs to adapt to the new level and will face challenges.

Some of the challenges faced by newly promoted senior leaders include their need to develop new patterns of thinking and behaving (Charan et al., 2011); their need to develop advanced interpersonal and social skills (Kets de Vries, 2006; Lombardo \& Eichinger, 1995); moving from operational to strategic mode (Bebb, 2009); fear, anxiety and 
self-doubt (Argyris, 1991); lack of emotional intelligence (Goleman, 1996); lack of follow-through and overdependence (Denton \& Van Lill, 2006); loss of identity, balancing people and tasks (Hawkins \& Smith, 2013); misjudging the new situation and the leader's strengths and vulnerabilities (Watkins, 2003); and getting buy-in from their new team (Martin, 2015).

Leaders' abilities to cope at higher levels are linked to their abilities to perceive and manage complexity. Rooke and Torbert provide a framework that outlines seven levels of developmental action logics: Opportunist, Diplomat, Expert, Achiever, Individualist, Strategist and Alchemist. Each level represents a higher level of development (Rooke \& Torbert, 2005). Kegan distinguishes between orders of complexity and people's ability to cope with the increased complexity with his object-subject principle. He asserts that people are capable of managing only a certain level of complexity at a given time and that they require assistance to master the next level. Lack of support during transitions to the next level of complexity may result in suffering (Kegan, 1994) as well as low morale and financial loss (Martin \& Gentry, 2011). The potentially traumatic nature of transitions clearly opens the space for considered support such as transition coaching.

In summary, significant theory exists regarding leadership and job levels and the challenges faced during the transition to a higher level.

\section{Coaching}

To support leaders-in-transition, organisations are increasingly implementing leadership development programmes (Kates \& Downey, 2005). Coaching is one form of support offered (Weinstock, 2011); however, although development of leaders is often stated by organisations as one of their primary concerns, there is debate as to whether enough is done to put words into action (Avolio \& Hannah, 2008).

Executive coaching is a short-term interactive process between a coach and a leader aimed at improving leadership effectiveness by enhancing self-awareness and the practice of new behaviours (Kombarakaran et al., 2008). Transition coaching is a relatively new field of coaching. It is a specialisation of executive coaching that aims to facilitate career transitions by helping leaders identify critical issues they face as a result of the transition; define the expectations of their stakeholders; gain an outside perspective on their new role; and communicate more effectively within the organisation (Witherspoon \& Cannon, 2004).

Transition coaching can play an important role in accelerating job transition (Sutton, 2008). Important considerations for transition coaching include the timing of coaching, the specific role of the coach, taking into account the business realities during the personal journey, understanding what skills and behaviours are required, increasing selfawareness, establishing goals and creating an action plan (Sutton, 2008).
Research investigating the role of transition coaching is limited with only one empirical study found thus far (Reynolds, 2011) and to our knowledge no such research has been published in the South African context. Reynolds used an Interpretative Phenomenological Analysis approach with a sample of six recently promoted senior leaders, to explore the meaning that coaching had for them during their transition. The findings include evidence that coaching assists transitioning leaders in overcoming a sense of vulnerability, developing new personal, social and cognitive skills and finding new meaning and purpose in their lives. The research was limited to senior leaders and did not include the view of coaches, HR practitioners and line managers as is the case in this study. Reynold's study also did not report on the coaching process but concentrated on the outcomes of the coaching only.

It is evident from literature that transition coaching could potentially play an important role during career transitions, but limited empirical research has been conducted on how the transition coaching process should be designed.

\section{Research design Research approach}

This interpretevist qualitative study employed a constructivist grounded theory approach (Charmaz, 2014). The interpretevist paradigm is purported by numerous scholars in the field of social research as an appropriate paradigm to uncover social truths as is the case in this study and therefore an appropriate research approach (Babbie \& Mouton, 2001; Creswell, 2003; Dreher, 1994; Willis, 2007). Grounded theory was selected as specfic methodology because of the lack of existing theory on transition coaching (Goulding, 2002). The research followed the process suggested in grounded theory whereby a theory is developed that is grounded in data that are systematically gathered and analysed according to a specific process. The theory evolves during the research process itself and is a product of continuous interplay between analysis and data collection (Glaser \& Strauss, 1967; Strauss \& Corbin, 1990).

\section{Research method}

\section{Research setting}

Participants were interviewed face-to-face as well as via telephone, given the remote location of some participants relative to the researcher and given the paucity of senior leaders who received coaching during their transition.

\section{Sampling}

Purposeful, theoretical sampling, consistent with the requirements of grounded theory research, was used to identify 16 participants from various organisations (Strauss \& Corbin, 1990). Practically, this implied starting with the most likely source of data (a recently transitioned senior leader known to the researcher), leading on to coaches who practised transition coaching, followed by the custodians of coaching in organisations and concluding with line managers of 
recently promoted senior leaders. The sampling strategy was informed by the outcome of the constant analysis and comparison process prescribed by grounded theory (Charmaz, 2014). In total eight senior leaders, five coaches, two HR practitioners and one line manager were interviewed in that order. The sequencing of interviews was deliberate and led to insights starting from the most direct (transitioning leader) to the least directly impacted (line manager). This sampling strategy collected data in accordance with grounded theory principles of constant data collection, analysis and comparison, giving preference to the richest source of data needed next to address the research question at hand (Charmaz, 2014). Although gender and race were not specific inclusion criteria in this study, all four SA racial groups (white, coloured, Indian and black) and equal gender grouping were represented in the sample.

\section{Entrée and establishing researcher roles}

Access to the recently promoted senior leaders was gained either through direct connection with the researcher or via the companies' HR departments. In the case of the latter, official permission was obtained from the head of HR of the organisation. Coaches, HR practitioners and the line manager were sourced from the researcher's personal network. In all cases the participants signed informed consent forms.

\section{Data collection methods}

Open-ended interviews, lasting approximately $1 \mathrm{~h}$ were conducted with each participant individually. Interview questions included high-level questions, followed by prompts around how participants experienced the coaching process and what aspects of the coaching worked or did not work for them. Interviews were digitally recorded, transcribed and analysed. Analysis and memo writing occurred after each interview to inform the interview strategy and questions for the next participant in accordance with grounded theory principles of constant comparison and theoretical sampling (Charmaz, 2014; Goulding, 2002). As an example, in the first interview the recently promoted senior leader made a distinction between being promoted internally versus externally. While this concept was not part of the original interview prompts, the coding and memo writing process following this interview revealed the potential importance of this phenomenon. This led the researcher to consciously enquire about this in subsequent interviews.

\section{Data analyses}

Grounded theory allows for a number of different data analysis options (Goulding, 2002). In this study line-by-line coding, focussed coding and category identification through extensive memo writing were followed (Charmaz, 2014).

Throughout the research the core principles of grounded theory were employed, namely, theoretically sensitive coding, constant comparison and theoretical sampling (Glaser \& Strauss, 1967). This implied going back into the field to reinterview certain participants as new themes emerged
(Strauss \& Corbin, 1990). As an example, during the fifth interview a senior leader remarked how important the use of theoretical frameworks was in his coaching. During the coding of this interview (carried out straight after the interview) and the subsequent update of the memo, a new theme emerged that led the researcher to re-interview some of the participants in order to obtain their view on this aspect.

The qualitative analysis software application Atlas.TI was used for the analysis process. To ensure data quality, the transcribed interviews were sent back to the participants for member checking (Lincoln \& Guba, 1985). A researcher's diary was also kept to help keep track of the research process and to apply reflexivity.

\section{Findings}

The findings from the analysis of the 16 interviews with recently promoted senior leaders (P1 to P8), coaches (C1 to C5), HR practitioners (HR1 and HR2) and a line manager (M1) were grouped into two themes in line with the research objectives: initiating coaching and the coaching process itself.

\section{Initiating coaching}

The phenomenon of initiating transition coaching contains five sub-themes as summarised in Table 1.

\section{Timing}

Irrespective of whether the idea of coaching was initiated by the recently promoted senior leader (P1, P5) or their line managers (P2, P3, P4, P6, P7, P8), in all instances it was undertaken when the incumbent had already shown signs of distress in the new role. This points to the fact that transition coaching is not something that organisations take seriously and apply in a pre-emptive manner. It seems to be used for remedial effect. $\mathrm{C} 1$ notes that the transition coaching she has done has been almost accidental as part of a 'brushstroke' approach by organisations to coaching their leaders, not specifically aimed at transitioning leaders. This is especially true for internally promoted senior leaders. In one instance, C2 only became involved 6 years after a promotion when issues of the person not adjusting to the new role reached crisis levels: 'It is not front of mind for a company to say we are promoting you therefore we think you should get the support' (C2, female, Coach). HR1's company has no specific

TABLE 1: Theme 1: Initiating coaching

\begin{tabular}{ll}
\hline Sub-theme & Key insights \\
\hline 1. Timing of coaching & $\begin{array}{l}\text { Coaching starts too late; no explicit transition coaching; } \\
\text { coaching used for remedial effect; coaching should start } \\
\text { before the transition. }\end{array}$ \\
2. Duration of coaching & $\begin{array}{l}\text { Interventions are too short (<6 months); coaching is } \\
\text { expensive; more frequent coaching immediately after } \\
\text { transition; less frequent sessions for up to } \\
18 \text { months to 3 years later on. }\end{array}$ \\
3. Selecting a coach & $\begin{array}{l}\text { Coachee should be given options; personal connection } \\
\text { between coach and coachee is important. }\end{array}$ \\
4. Logistics & $\begin{array}{l}\text { Off-site (away from office) coaching is preferable; coach } \\
\text { and coachee must be pragmatic and flexible. }\end{array}$ \\
5. Contracting & $\begin{array}{l}\text { Three-way contract between coachee, coach and } \\
\text { organisation needed; Coach-coachee confidentiality is } \\
\text { important to the exclusion of the organisation. }\end{array}$ \\
\hline
\end{tabular}


process for assigning a coach to a newly promoted senior leader. Instead the business can request a coach at any time, so it is up to the line manager to decide whether the incumbent needs a coach. Alternatively, if a person is nominated for a leadership development programme they may encounter coaching as part of design, but this is not necessarily linked to a promotion.

The question of whether to initiate the coaching before or after the promotion drew varied responses. On the one hand, P4, P6, C3 and M1 felt that coaching should start before the promotion. These participants agreed that there should be between one and five sessions before the promotion, a number of sessions in short succession shortly afterwards and then fewer and more spread out sessions for ongoing support for up to 2 years (M1, P1, P5, P6). C3 warned that transition coaching must be pre-emptive: 'we tend to only look for help when there's a burning platform' (C3, male, Coach). This is echoed by M1:

if you are going to put your feet wrong - you are going to do it right there in the early stages where you want to set the agenda. You want to set the scene. You do not want to make mistakes before you have even started. (M1, female, Manager of transitioning leaders)

Those who think that coaching should only start after the candidate enters the role (P7, C1, HR2) have different reasons for stating this. P7 feels that the candidate needs to spend a few months in the new position to understand what they are struggling with in order to optimise the coaching. C1 was concerned that transition coaching before a promotion could be confused with career coaching while HR2 was worried that transition coaching before a promotion could have legal implications should the promotion not materialise. C3 provides a pragmatic solution to this: 'coaching should start as soon as the news is broken' (C3, male, Coach).

\section{Duration}

While all the participants interviewed were unanimous that transition coaching should continue for an extended period of time of up to 3 years (HR2), only one participant experienced such an extended intervention of 18 months which he considered to be very beneficial to his learning process.

Most of the participants reported interventions ranging between 6 and 10 sessions over a period of less than a year. It was felt that this is inadequate:

Typically we sort of put a 12 week intervention or maybe put a 6 month intervention in but we never talk about the 2 year and 3 year period. Unfortunately, I think coaching is great and it has its place, but I think we still think too tactically about the learning journey. (HR2, female, HR practitioner)

Behaviour doesn't change in 12 months. (M1, female, Manager of transitioning leaders)

The reasons for these limited interventions were cited as cost and a misunderstanding of the transition and transformation process. In HR2's experience there is a perception from line managers that if the incumbent has not 'made it after six months on the job as a leader then we shouldn't have promoted him' (HR2, female, HR practitioner).

Suggested solutions include initial frequent coaching sessions (every 2 weeks) for the first 3 months to assist with immediate issues and then less frequent sessions of once a month or even 2 months for up to at least 18 months, but preferably up to 3 years.

\section{Coach selection}

The process of selecting a coach varied between organisations. In most cases the coachee was given a choice of coaches either through an interview process or a so-called chemistry session (P3, P5), or by reviewing coaches' CVs (P8). HR2's organisation uses a panel of coaches and assigns a coach based on a specific skills-set needed in the intervention. The importance of coach selection was highlighted by P7 (an actuary) who stated that it was very important to him that his coach had the ability to think analytically and conceptually. The coach he selected was an engineer.

\section{Logistics}

The issue of where and what time coaching should take place elicited varied responses. P1 preferred a location far away from work in a relaxed environment such as a restaurant or hotel and at a time of day that was convenient. The neutral location energised him sufficiently to allow him to engage in the coaching. P2 on the other hand was coached at her office, but she does feel that it would have been better to be coached away from the office as she would have felt more free to talk about 'what is bothering her'. P4 concurred that even though he was coached at the office he would have preferred to be out of the 'buzz' of the office. P5 and P7 experienced both in and out of the office scenarios and both preferred the off-site location.

It would appear from the responses that off-site coaching is preferable, but $\mathrm{C} 1$ sums it up well when she states that: '... it is up to the coachee to make the call on what suits them and for the coach to be flexible and accommodating' (C1, female, Coach).

\section{Contracting}

All the coaches reported going through a contracting phase. In all cases there was at least one session at the start where an organisational representative provided input into the coaching process. There were some variations. $\mathrm{C} 1$ has two sessions with the organisation, one at the start to set goals and one at the end to provide feedback, although she has observed that for executive-level coachees the organisations seem to be less involved in the coaching process.

The importance of confidentiality during the contracting phase and throughout the intervention is stressed:

The client might think you are in cahoots with the organisation and they might want to use you to do performance management. (C2, female, Coach) 
I never meet - except for the first conversation that they ask me they want me to coach so and so. After that I never meet alone with any of the organisational representatives. Never. That creates suspicion. The minute you talk it creates suspicion. (C4, female, Coach)

\section{The coaching process}

The coaching process theme yielded four sub-themes (Table 2).

\section{Managing the coaching process}

Goal setting emerged as an important part of the transition coaching process. Coaching goals provided structure (P1, P4) and helped coachees stay accountable:

... once you kind of put it down on a piece of paper, even if it was only your piece of paper, it suddenly becomes much more tangible ... Just writing it down is incredibly powerful. (P5, male, Transitioning leader)

C3 uses goal setting as a standard practice to involve line managers indirectly in the coaching process:

They (line managers) are the ones who see you dropping the ball in the areas you want to develop. So if you're lacking assertiveness and in the next Exco meeting you're not speaking up then they can hold you accountable. (C3, male, Coach)

Two coachees felt strongly about the benefits of their coaches summarising the coaching sessions and sharing this with them. P5's coach created a two- to three-page, typed summary after each coaching session. This was useful to him in that it allowed him to reflect on the coaching session between sessions, as well as serving as a reminder of coaching goals. Even after the coaching ended, P5 was using the coaching summaries (comprising some 40 pages) to remind himself of his journey and his progress to date. For P7 the summaries acted as reference to books and resources he could consult.

Active experimentation emerged as a strong sub-theme (P1, P2, P3, P6, P7, P8). P8 experimented with body and verbal language. $\mathrm{P} 6$ practised in a mirror to overcome her public shyness. P7 provided another example:

Go into a meeting and try and come out of it with the other party feeling: I love this guy. Or go into a meeting and try and get the

TABLE 2: Theme 2: The coaching process.

\begin{tabular}{ll}
\hline Sub-theme & Key insights \\
\hline $\begin{array}{l}\text { 1. Managing the } \\
\text { coaching process }\end{array}$ & $\begin{array}{l}\text { Setting goals are important to keep coachees accountable; } \\
\text { goal setting focusses the intervention; coaches should } \\
\text { summarise coaching sessions to allow reflection and } \\
\text { referencing; coaches should encourage coachees to } \\
\text { reflect and experiment with different thinking and } \\
\text { behaving in between sessions; coachee must } \\
\text { reflect on experiments in sessions. }\end{array}$ \\
$\begin{array}{ll}\text { 2. Using theory } & \begin{array}{l}\text { Frameworks, theory and models shared by coaches helped } \\
\text { coachees understand their new roles and themselves; } \\
\text { psychometric assessments help create self-awareness. }\end{array} \\
\text { 3. Consulting external } \\
\text { parties }\end{array} \quad \begin{array}{l}\text { Support from line manager helps support the coachee; } \\
\text { HR should keep an arms-length distance but may } \\
\text { intervene if coaching results not evident; involving a } \\
\text { mentor is beneficial; involving the coachee's team } \\
\text { helps the team understand the coachee change process. }\end{array}$ \\
$\begin{array}{l}\text { Map the coachee's network; identify network } \\
\text { improvements; expand coachee's network } \\
\text { via formal and informal ways. }\end{array}$ \\
\hline
\end{tabular}

guy at the end going you really struck me as someone with very high EQ. (P7, male, Transitioning leader)

Reflection was used in various ways including obtaining clarity of thinking (P3), identifying alternative solutions (P4), feeling unjudged (P5) and creating awareness of positive thoughts (P6). C1 distinguishes between assisted reflection, led by the coach and self-reflection, performed by the coachee outside of the coaching sessions. C4 uses reflection to close the active experimentation learning loop.

In general, there seems to be a pattern of the coaching, creating awareness in the client, of the need to change, encouraging the client to practise and experiment with different behaviours to see what works and finally to reflect back in the coaching session on what worked or did not work and the reasons for it $(\mathrm{C} 1, \mathrm{C} 2, \mathrm{C} 3, \mathrm{C} 4)$.

\section{Using theory}

A number of participants valued the inclusion of theoretical models and frameworks in the coaching process by their coaches. Coaches shared cognitive behavioural theory (P1), leadership theory (P4), video clips (P5) and the Leadership Pipeline model (C1). For P7 as a technically minded individual it was crucial that his coach provided him with theoretical frameworks to allow him to understand what process he was undergoing. Socratic questioning helped him to listen to people instead of telling them what to do.

A number of participants reported using psychometric assessments as input into the coaching process. This include 360-degree review, Enneagram, Myers-Briggs, Insights, Organic scorecard and repertoire grid to name a few. The benefits of these assessments range from comfort that my coach knows me (P7), increased self-awareness (P8, C3, C5) and getting the coaching 'unstuck' (C4).

\section{Consulting external parties}

The classical three-way meeting between the coach, coachee and line manager at the start of the coaching process to align on goals and at the end to provide feedback were present in a number of instances (P1, P3, P5, C1, C3). For C3: 'If the line manager does not enforce the shift to the desired behaviour it probably won't happen' (C3, male, Coach). HR1 feels it is sufficient to receive occasional feedback from the coach while HR2 feels that the organisation should take a backseat as the results of the coaching should be visible. If not she will intervene:

I am not seeing the behaviour. I am not seeing the values demonstration. I am not seeing the strategic thinking. I am not seeing the connectedness with people, whatever the case may be. Those tell-tale signs should then say - okay coach I need to check in. (HR2, female, HR practitioner)

While being coached, some coachees found it useful to have a mentor. For some this was a formal process (P2) where their line manager appointed an internal mentor to support their transition, while for others it was an informal process. It 
would appear that using a mentor at the same time as being coached is not a standard practice, but for those who did have a mentor the effect was positive.

An interesting phenomenon that emerged from this research is where coaches C2 and C3 involved the newly promoted leader's team in the coaching process. For C2 this was almost out of frustration because the transformation that her client underwent was met with suspicion by her team. It was only after three facilitated sessions with the leader and her team that trust was restored to some extent. For C2 there is no other way of coaching people who are being groomed for leadership' (C2, female, Coach) than to involve their teams at some point while for C3 involving the team was a way to bring in the systemic aspect of a senior corporate position.

\section{Networking}

P1 and his coach spent some time analysing his network:

we spent quite a bit of time to draw a picture of the people in my work life: who are the people that stress me out, who are the players, the actors in this great play at work. (P1, male, Transitioning leader)

C1 and C4 reported using a similar approach with their clients to help them build new relationships.

P3 expanded her network on a senior level, P5 spent time on his international network and P6 focussed on building networks outside of her regional office. All three participants found this exercise helpful in their new role. $\mathrm{C} 1$ advises her clients to build networks by meeting face-to-face either formally (using work as an excuse to introduce yourself) or informally (dropping in and introducing yourself as the new person).

\section{Ethical considerations}

This research was approved by the ethics committee of the University of Stellenbosch. All participants signed informed consent forms where their confidentiality, anonymity and rights were explained.

\section{Discussion}

The main aim of this research was to investigate how a coaching intervention should be designed to explicitly support leaders who are promoted into senior leadership positions. Two main themes emerged from the empirical data: aspects to take into account when initiating the coaching process and considerations when facilitating the coaching process itself. These findings provide practical suggestions for designing transition coaching interventions aimed at supporting leaders when they are appointed into senior leadership positions.

\section{Initiating the coaching process}

The most prominent finding of this research is that transition coaching is not yet seen as a distinct coaching sub-discipline by organisations, despite the fact that the coaching fraternity considers transition coaching to be a specialisation of executive coaching (Witherspoon \& Cannon, 2004). As a result coaching is not used explicitly and pre-emptively to assist leaders during their promotion into senior leadership positions. For the participants in this research, transition coaching was not part of the default leadership development tools used by their organisations. Organisations use a number of methods to train new leaders such as mentoring and coaching, 360-degree feedback, leadership training, job assignments, self-other agreement, use of self-narrative and life stories and action learning among others (Day, Fleenor, Atwater, Sturm \& McKee, 2014; Fleenor, Smither, Atwater, Braddy \& Sturm, 2010; Ligon, Hunter \& Mumford, 2008). Some of these coaching is unique in that it is tailored to the individual and concentrates on behavioural change. Coaching puts into action the suggestion of change that other leadership development programmes profess (Kombarakaran et al., 2008).

There is a clear need for a more systematic approach to supporting new leaders that include both traditional leadership development programmes and personal coaching (Martin, 2015). This research confirms the notion that coaching at key career transition points, such as a promotion into a senior position, is a powerful mechanism to help ensure the incumbent's success (Simpson, 2010).

The findings of this research suggest that to avoid getting off to a wrong start, coaching should commence before the promotion (as soon as the announcement is official) to help the new senior leader design an action plan. There should then be regular (every 2-4 weeks) coaching sessions for the first 6 months, after which less frequent (every 2-3 months) sessions should occur for up to 3 years. These results differ from the notion that coaching for senior leaders should only start after the first 90 days (Sutton, 2008) and concurs that the results of the first 90 days in a senior position often set the tone for failure or success (Watkins, 2009).

The reason that transition coaching is not used more pervasively can to some extent be attributed to the high cost associated with the process. This was certainly the case for a number of participants in this research and is in line with other research findings that suggest that coaching is often lumped together with expensive interventions such as training programmes without considering the unique individual benefits that coaching brings (Simpson, 2010). On the other hand, if the high cost associated with an unsuccessful promotion to both the individual and the organisation is considered (Martin, 2015; Watkins, 2009), and the high likelihood of failure (Witherspoon \& Cannon, 2004) perhaps the cost of a 3-year long coaching intervention as suggested above, is not as significant as is currently perceived.

An important part of initiating the coaching process is matching the coach and coachee. Both the new leader and the organisation's fit to the coach must be considered (Weinstock, 2011). The findings from this research suggest that the new leader must be given a choice of coaches to consider. This is 
particularly important because not all coaches may be skilled in the specialisation of transition coaching and transition coaching is considered challenging for the coaching profession. New senior leaders are typically ambitious, intelligent, energetic and restless individuals, which implies that the coach must be able to cope with a wide range of issues and be able to move at a fast pace (Reynolds, 2011). A strong case can therefore be made to include a specific focus on transition coaching when training new coaches.

These research findings suggest that coaching sessions should ideally be conducted away from the office environment to create a space free from mental clutter. It is important however that pragmatism and flexibility be applied to customise the coaching progress to suit both coach and coachee. This is echoed by other research (Kaufman, 2006; Sammut, 2014).

\section{Managing the coaching process}

Once the coaching process is underway, a number of key elements must be present to help guide the transition coaching process to success. The first such element as revealed by the findings, is the importance of managing the coaching process by setting goals, encouraging active experimentation in between coaching sessions and constant reflection.

Because of the inherently complex and unstructured nature of the new role and the challenges that senior leaders face (Peltier, 2010), it is crucial that goals are set to enable the incumbent to focus and to develop their current capacity (Grant, Passmore, Cavanagh \& Parker, 2010). These goals enable the newly promoted leader, their team and line manager to identify critical issues that need addressing and to find alignment (Freeman, 2011, Witherspoon \& Cannon, 2004). This research shows that goal setting during transition coaching is a crucial step and that these coaching goals must take into account the organisational needs (Gray, 2006; Kahn, 2014). This research also shows that setting transition coaching goals and sharing this with a wider audience help to keep coachees accountable not only to themselves, but to their team and line managers.

Reflection during and between coaching sessions and active experimentation between coaching sessions by the new leader appear to be important elements of a successful transition coaching intervention. New leaders often have incomplete, biased and irrelevant mental models when they take up the new position. They also often underestimate the complexity of the new role they take on, and this causes them to focus selectively on problems they feel comfortable to tackle (Freeman, 2011; Hill, 1992). The role of the transition coach is to help create awareness of these limiting assumptions through reflection (Reynolds, 2011) and encouraging active experimentation to refute strongly held notions of what is possible (Schön, 1991). The importance of reflection and active experimentation is echoed by the findings of this research whereby all the coaches interviewed profess to use reflection and active experimentation in their transition coaching practice.

The findings suggest that the use of assessments and other theoretical frameworks were utilised frequently to provide a baseline and scaffolding within which the transition coaching was executed. Literature also suggests the use of assessments in transition coaching to determine coaching needs (Grant et al., 2010; Kaufman, 2006; Witherspoon \& Cannon, 2004).

Involving third parties such as line managers and mentors emerged as an important contributing factor to transition coaching success. One use of this technique is for the coach to obtain feedback from others to help the new leader understand their limiting assumptions (Freeman, 2011). Mentors and line managers can also support the coaching agenda by being made aware of the coaching goals and to provide support and guidance during the coaching intervention. Findings from this research even suggest that the new leader's team should be involved in the process to enable an understanding of the change process and to provide a systemic angle to the coaching.

Finally, this research shows that the transition coach should help the new leader identify and build a strong network of people relevant to the new role. This finding is in line with other research that shows the importance of building a strong network (Clutterbuck \& Megginson, 1999; Terblanche, 2014).

\section{Practical implications}

A senior career transition is a uniquely challenging point in a leader's career with specific and well-known obstacles to overcome. The findings of this research suggest that the process of initiating and managing the transition coaching intervention could be specifically designed to address these known challenges. This gives impetus to the idea of recognising 'transition coaching' as a distinct coaching subdiscipline and for HR practitioners to take note of the potential benefit of such a tailor-made intervention.

HR practitioners should take note of the timing of initiating coaching (as soon as possible after the appointment is official), the frequency of coaching (one or two sessions before the role take-up, $6-10$ during the first 6 months and thereafter one session every $2-3$ months for up to 3 years). HR practitioners must also ensure that coach-coachee matching provides a number of options to the coachee, that clear coaching goals are set that consider the organisational goals and that transition coaches employ reflection and active experimentation in their coaching model. Line managers, peers and team members of the new leaders must also be involved in the coaching process through input (e.g. 360 assessments), mentoring and goal sharing.

\section{Limitations of the study}

Although the participant selection included a diversity of perspectives which included new leaders who were coached, 
transition coaches, HR practitioners and a line manager, diversity could have been increased by including the perspectives of the new leader's peers and subordinates.

\section{Conclusion}

Literature indicates that there are significant challenges faced by newly promoted senior leaders. The cost of failure is high to both the individual and the organisation. Transition coaching has been shown to be a valuable support for leadersin-transition. This research provides empirical evidence of the need for transition coaching and the lack of its use at present. Practical suggestions are made to assist HR practitioners and coaches to design coaching interventions specifically aimed at assisting transitioning leaders. These include:

- starting transition coaching as soon as the appointment is official

- continuing for at least 3 years with a session every 2-3 weeks for the first 6 months and a session every 2-3 months thereafter

- providing the coachee with a number of coach options

- allowing coaching to happen outside the office environment.

As part of the coaching process, the following aspects must be present:

- Clear coaching goals must be set which take into account the organisational needs.

- The coach's model must include reflection and active experimentation.

- Assessments and theoretical frameworks must be used during the coaching intervention to help create selfawareness.

- Mentors, line managers and the new leader's team must be involved in the coaching process.

- Building a new network must be an explicit part of the coaching process.

Coaching can provide effective support for leaders. If customised for career transition as suggested in this research, transition coaching may be able to provide a humane way to support ambitious, talented individuals with the significant challenges they face during promotions into senior leadership positions.

\section{Acknowledgements Competing interests}

The authors declare that they have no financial or personal relationships which may have inappropriately influenced them in writing this article.

\section{Authors' contributions}

N.H.D.T. conducted the research and wrote the article as part of his PhD project. R.M.A. and S.v.C-P. supervised his research and reviewed the article.

\section{References}

Argyris, C. (1991). Teaching smart people how to learn. Harvard Business Review, 1 May-June, 99-109.

Avolio, B.J., \& Hannah, S.T. (2008). Developmental readiness: Accelerating leader development. Consulting Psychology Journal: Practice and Research, 60(4), 331-347. https://doi.org/10.1037/1065-9293.60.4.331

Babbie, E., \& Mouton, K. (2001). The practice of social research. Cape Town: Oxford University Press.

Bebb, S.S. (2009). The structure of role transition: A phenomenological study of successful executives from five countries. International Journal of Leadership Studies, 4(2), 223-243.

Charan, R., Drotter, S., \& Noel, J. (2011). The leadership pipeline. San Fransisco, CA: Wiley.

Charmaz, K. (2014). Constructing grounded theory. Thousand Oaks, CA: Sage.

Chinyamurindi, W.T. (2012). An investigation of career change using a narrative and story-telling inquiry. SA Journal of Human Resource Management/SA Tydskrif vi, 10(2), 1-11. https://doi.org/10.4102/sajhrm.v10i2.447

Clutterbuck, D., \& Megginson D. (1999). Mentoring executives and directors. Oxford: Butterworth-Heinemann.

Creswell, J.W. (2003). Research design: Qualitative, quantitative, and mixed methods approaches. (2nd edn). Thousand Oaks, CA: Sage.

Day, D., Fleenor, J., Atwater, L., Sturm, R., \& McKee, R. (2014). Advances in leader and leadership development: A review of 25 years of research and theory. The Leadership Quarterly, 25, 63-82. https://doi.org/10.1016/j.leaqua.2013.11.004

Denton, J., \& Van Lill, J. (2006). Managerial derailment. Vilakshan, XIMB Journal of Management, August, 231-250.

Dotlich, D.L., Noel, J.L., \& Walker, N. (2004). Leadership passages. San Fransisco, CA: Wiley.

Dreher, M. (1994). Qualitative research methods from the reviewer's perspective. In J. Morse (Ed.), Critical issues in qualitative research methods (pp. 281-297). Thousand Oaks, CA: Sage.

Fleenor, J.W., Smither, J.W., Atwater, L.E., Braddy, P.W., \& Sturm, R.E. (2010). Self-other rating agreement in leadership: A review. The Leadership Quarterly, 21(6), 10051034. https://doi.org/10.1016/j.leaqua.2010.10.006

Freedman, A.M. (2011). Some implications of validation of the leadership pipeline concept: Guidelines for assisting managers-in-transition. The PsychologistManager Journal, 14, 140-159. https://doi.org/10.1080/10887156.2011.570146

Glaser, B., \& Strauss, A. (1967). The discovery of grounded theory: Strategies for qualitative research. Chicago, IL: Aldine Publishing.

Goleman, D. (1996). Emotional intelligence: Why it can matter more than IQ. London: Bloomsbury.

Goulding, C. (2002). Grounded theory: A practical guide for management, business and market researchers. Thousand Oaks, CA: Sage.

Grant, A.M., Passmore, J., Cavanagh, M.J., \& Parker, H. (2010). The state of play in coaching today: A comprehensive review of the field. International Review of Industrial and Organizational Psychology, 25, 125-167. https://doi.org/10.1002/ 9780470661628.ch4

Gray, D.E. (2006). Executive coaching - Towards a dynamic alliance of psychotherapy and transformative learning processes. Management Learning, 37(4), 475-497. https://doi.org/10.1177/1350507606070221

Hawkins, P., \& Smith, N. (2013). Coaching, mentoring and organizational consultancy. (2nd edn.). Maidenhead: McGraw Hill Education, Open University Press.

Hill, L.A. (1992). Becoming a manager: Mastery of a new identity. Boston, MA: Harvard Business School Press.

Jaques, E. (1996). Requisite organisation. Gloucester, MA: Cason Hall.

Kahn, M.S. (2014). Coaching on the axis: Working with complexity in business and executive coaching. London: Karnac Books.

Kates, A., \& Downey, D. (2005). The challenges of general manager transitions. In R.B. Kaiseer (Ed.), Filling the leadership pipeline (pp. 45-68) Greensboro, North Carolina: Centre for Creative Leadership.

Kaufman, B. (2006). The role of executive coaching in performance management. In Patricia Coate (Ed.), Handbook of business strategy (pp. 287-291). UK: Emerald Group Publishing.

Kegan, R. (1994). In over our heads: The mental demands of modern life. Cambridge, MA: Harvard University Press.

Kets de Vries, M. (2006). The leadership mystique - Leading behaviour in the human enterprise. London: FT Prentice Hall.

Kombarakaran, F., Yang, J., Baker, M., \& Fernandes, P. (2008). Executive coaching: It works! Consulting Psychology Journal: Practice and Research, 60(1), 78-90. https://doi.org/10.1037/1065-9293.60.1.78

Ligon, G.S., Hunter, S.T., \& Mumford, M.D. (2008). Development of outstanding leadership: A life narrative approach. The Leadership Quarterly, 19(3), 312-334. https://doi.org/10.1016/j.leaqua.2008.03.005

Lincoln, Y., \& Guba, E. (1985). Naturalistic inquiry. Newbury Park, CA: Sage.

Lombardo, M., \& Eichinger, R. (1995). Preventing derailement: What todo before it's too late. Greensboro, NC: Centre for Creative Leadering.

Manderscheid, S.V., \& Ardichvili, A. (2008). A conceptual model for leadership transition. Performance Improvement Quarterly, 20(1), 113-129. https://doi. org/10.1002/piq.20006 
Martin, J., \& Gentry, W.A. (2011). Derailment signs across generations: More in common than expected. The Psychologist-Manager Journal, 14, 177-195. https:// doi.org/10.1080/10887156.2011.595973

Martin, J.F. (2015). Ascending to the C-suite. New York: McKinsey \& Company.

Nzukuma, K.C.C., \& Bussin, M. (2011). Job-hopping amongst African Black senior management in South Africa. SA Journal of Human Resource Management/SA Tydskrif vir Menslikehulpbronbestuur, 9(1), 12. https://doi.org/10.4102/sajhrm. v9i1.360

Olivier, A., \& Page, T. (2017). Rewriting the rules for the digital age: 2017 human capital trends report for South Africa. Deloitte University Press.

Peltier, B. (2010). The psychology of executive coaching: Theory and application. (2nd edn.). New York: Routledge.

Reynolds, G. (2011). Exploring the meaning of coaching for newly appointed senior leaders in their first twelve to eighteen months in role. International Journal of Evidence Based Coaching and Mentoring, June (Special Issue No. 5), 39-53.

Rooke, D., \& Torbert, W. (2005). Seven transformation of leadership. Harvard Business Review, 83(4), 66-76.

Sammut, K. (2014). Transformative learning theory and coaching: Application in practice. International Journal of Evidence Based Coaching and Mentoring, 8, 39-53.

Schön, D.A. (1991). The reflective practitioner: How professionals think in action. Aldershot: Ashgate Publishing Ltd.

Simpson, J. (2010). In what ways does coaching contribute to effective leadership development? International Journal of Evidence Based Coaching and Mentoring, (Special Issue No. 4), 114-134.
Strauss, A., \& Corbin, J. (1990). Basic qualitative research: Grounded theory procedures and techniques. Newbury Park, CA: Sage.

Sutton, J. (2008). Coaching leadership transitions. In The 2008 Pfeiffer annual leadership development (pp. 199-207). Wiley.

Terblanche, N. (2014). Knowledge sharing in the organizational context: Using social network analysis as a coaching tool. International Journal of Evidence Based Coaching and Mentoring, 12(2), 146-164.

Theeboom, T., Beersma, B., \& Van Vianen, A. (2013). Does coaching work? A metaanalysis on the effects of coaching on individual level outcomes in an organizational context. The Journal of Positive Psychology, 9(1), 1-18. https://doi.org/10.1080/1 7439760.2013.837499

Watkins, M. (2003). The first 90 days. Boston, MA: Harvard Business School Press.

Watkins, M.D. (2009). Picking the right transition strategy. Harvard Business Review, 01 January, 47-53.

Weinstock, B. (2011). The hidden challenges in role transitions and how leadership coaching can help new leaders find solid ground. Holistic Nursing Practice, 25(4), 211-214. https://doi.org/10.1097/HNP.0b013e31822270ec

Willis, J. (2007). Foundations of qualitative research: Interpretive and critical approaches. Thousand Oaks, CA: Sage.

Witherspoon, R., \& Cannon, M.D. (2004). Coaching leaders in transition. In A.F. Buono (Eds), Creative consulting: Innovative perspectives on management consulting (p. 201). Information Age Publishing, Greenwich: Connecticut. 